\title{
Descontextualización, espectacularización y machismo en las narrativas mediáticas sobre violencia hacia las mujeres en Argentina. ¿Con la visibilización alcanza?*
}

\author{
Guillermo Romero* \\ Giuliana Pates**
}

Recibido: 2017-05-16 Enviado a pares: 2017-05-25

Aprobado por pares: 2017-07-18 Aceptado: 2017-07-25

DOI: 10.22395/angr.v16n31a2

\begin{abstract}
Resumen
El presente trabajo ofrece un análisis desde una perspectiva de género de los modos en que aparece representada la violencia hacia las mujeres en un conjunto acotado de medios gráficos de la República de Argentina. En este sentido, nos preguntamos: ¿qué hechos son nombrados como violencia? ¿Cómo se los interpreta? ¿Cómo se caracteriza a los sujetos intervinientes? ¿Qué recursos narrativos se emplean? ¿Cuáles son las voces autorizadas, los datos estadísticos y las agendas programáticas plasmadas en estos relatos? ¿Qué elementos intervinientes en la problemática son ocultados, ignorados o solapados? Y al mismo tiempo: ¿es posible advertir grietas, disensos, tensiones entre los distintos artículos periodísticos relevados? Estos son los principales interrogantes que intentaremos desandar a lo largo de estas páginas, procurando situarlos en su contexto legal y socio-político nacional, con el fin de contribuir a la imaginación de políticas públicas y prácticas sociales tendentes a lograr la igualdad de género.

Palabras clave: especulación; machismo; narrativas mediáticas; género; Argentina; políticas públicas.
\end{abstract}

* Este artículo constituye un primer avance del Proyecto de Investigación Orientada (PIO) denominado "Agendas del deterioro y sistema de miedos. Configuraciones mediáticas en torno a la 'inseguridad' en informativos audiovisuales nacionales, su circulación y apropiación en la vida cotidiana de los públicos", con sede en la Facultad de Periodismo y Comunicación Social de la Universidad Nacional de La Plata, dirigido por la Dra. Florencia Saintout y financiado por la Defensoría del Público de Servicios de Comunicación Audiovisual y el Consejo Nacional Investigaciones Científicas y Técnicas (Conicet), ambos de la República Argentina.

** Instituto de Estudios Comunicacionales en Medios, Cultura y Poder "Aníbal Ford". Facultad de Periodismo y Comunicación Social. Universidad Nacional de La Plata. institutoanibalford@perio.unlp.edu.ar

*** Instituto de Estudios Comunicacionales en Medios, Cultura y Poder "Aníbal Ford". Facultad de Periodismo y Comunicación Social. Universidad Nacional de La Plata. institutoanibalford@perio.unlp.edu.ar 


\title{
Decontextualization, espectacularización and machismo in media narratives about violence against women in Argentina. Is visibility enough?
}

\begin{abstract}
This work offers an analysis from a gender perspective of the ways in which violence against women is represented in a limited set of graphic media of the Argentine republic. In this sense, we ask ourselves: what facts are named as violence? How are they interpreted? How are the intervening subjects characterized? What narrative resources are used? Which are the authorized voices, statistical data, and programmatic agendas embodied in these stories? What intervening elements in the problem are hidden, ignored or overlapping? And at the same time, is it possible to notice cracks, dissensions, tensions between the different journalistic articles surveyed? These are the main questions that we will try to retrace throughout these pages, trying to place them in their national legal and socio-political context, in order to contribute to the imagination of public policies and social practices aimed at achieving gender equality.
\end{abstract}

Keywords: speculation; machismo; media narratives; gender; Argentina; public policies.

\section{Descontextualização, espetacularização e machismo nas narrativas midiáticas sobre violência contra as mulheres na Argentina. Com a visibilização basta?}

\begin{abstract}
Resumo
Este trabalho oferece uma análise sob uma perspectiva de gênero dos modos em que a violência contra as mulheres aparece representada num conjunto delimitado de meios gráficos da República Argentina. Nesse sentido, pergunta-se: que fatos são nomeados como violência? Como são interpretados? Como se caracterizam os sujeitos que intervêm? Que recursos narrativos são utilizados? Quais as vozes autorizadas, os dados estatísticos e as agendas programáticas registrados nesses relatos? Quais elementos intervenientes na problemática são ocultados, ignorados ou disfarçados? E, ao mesmo tempo, é possível advertir brechas, dissensos, tensões entre os diferentes artigos jornalísticos relevados? Estes são os principais questionamentos que se pretende desenvolver ao longo destas páginas, procurando posicioná-los em seu contexto legal e sociopolítico nacional a fim de contribuir para a criação de políticas públicas e práticas sociais que tendam a conseguir a igualdade de gênero.
\end{abstract}

Palavras-chave: Argentina, especulação, gênero, machismo, narrativas midiáticas, políticas públicas. 


\section{Metodología}

Para la construcción del corpus de notas periodísticas a analizar, recurrimos a la monitorización de medios de comunicación que realiza el Observatorio de Jóvenes, Comunicación y Medios ${ }^{1}$. A partir del mismo, se relevan todos los artículos publicados de lunes a viernes (excepto feriados) en las ediciones digitales de tres diarios de alcance nacional (Clarín, La Nación y Página 12) y uno de circulación local (El Día, de la ciudad de La Plata). Acorde con su especificidad teórica / temática, el relevamiento incluye todas aquellas noticias que mencionan "jóvenes" o cualquier otro término de la familia de palabras (como "adolescente" o "menor"), así como las que refieren a sujetos de entre 13 y 30 años de edad, más allá de la manera en que sean nombrados.

Esas notas se vuelcan en una matriz compuesta por diferentes parámetros que permiten, entre otras dimensiones, dar cuenta de los motivos temáticos trabajados en las noticias, las fuentes mencionadas, los territorios sociales donde suceden los hechos narrados y su ubicación geográfica. A fin de conformar un corpus acorde con los propósitos específicos de este artículo, circunscribimos nuestro análisis a aquellas noticias que fueron clasificadas bajo el motivo temático "violencia de género" en el período seleccionado. Este "filtro" nos arrojó como resultado un conjunto de 525 notas que constituyen nuestro principal campo material de indagación.

Para este trabajo, complementamos ese corpus incorporando las notas referidas a un caso de violencia de género no comprendidas dentro del relevamiento realizado por este Observatorio, así como los comentarios de lectores de los artículos analizados, también dejados de lado por dicha monitorización².

Si bien el proyecto en el que este trabajo se enmarca pretende reconocer y problematizar las múltiples configuraciones discursivas que reproducen y propagan estigmas, estereotipos y desigualdades, en este caso en particular nos centraremos específicamente en los modos en que se representan en las notas seleccionadas las violencias por razones sexo-genéricas, procurando indagar tanto en los puntos de acuerdo como en los disensos y matices que es posible advertir en tales representaciones.

En este sentido, por un lado, realizaremos algunas lecturas más generales sobre la totalidad de los textos recopilados, a fin de plantear unos trazos gruesos que permitan identificar "líneas de conjunto". Al mismo tiempo, nos centraremos especialmente en algunos de los "casos" más significativos que se sucedieron en el período seleccionado,

Perteneciente a la Facultad de Periodismo y Comunicación Social de la Universidad Nacional de La Plata. Agradecemos a los colegas y compañeros que trabajan en este espacio por su generosidad, compromiso y acompañamiento, especialmente a su directora, Andrea Varela, y a quienes forman parte del Área de configuraciones mediáticas sobre juventudes: Gonzalo Martin, Paula Posada Campoy, Alma Carrasco Calvi, Gonzalo Mamani Soraire y Sofía Rottoli. Mención aparte merecen Manuel Protto Baglione y Gonzalo Martin, quienes fueron fundamentales para mejorar este trabajo. Un agradecimiento especial a Tomás Viviani, co-director del Observatorio, amigo generoso y mentor principal de este artículo.

2 Ello obedece a que el relevamiento del Observatorio no contempla las notas que aparecen en los suplementos de "espectáculos" ni los comentarios de lectores/as, que a los fines de este trabajo interesaba analizar. Los artículos periodísticos incorporados pertenecen a los mismos medios y al mismo período que las demás notas analizadas. 
con el objetivo de analizar el modo en que se articulan en situaciones específicas los sentidos sociales en pugna. Como antesala a ese trabajo analítico, comenzaremos el recorrido poniendo de relieve el marco legal que pretende combatir la violencia contra las mujeres en Argentina, haciendo énfasis en la regulación de las narrativas mediáticas que en numerosas ocasiones constituyen una modalidad específica de esta violencia, reforzando, a su vez, todo el ordenamiento sexista del que forma parte.

\section{Violencia contra las mujeres y medios de comunicación: antecedentes y marco normativo en la República Argentina}

El trabajo se pregunta por las violencias así como por los modos en que éstas se representan en las narrativas mediáticas sujetas a análisis. Sin embargo, violencia no remite a una realidad universal e indiscutible. Su sentido no es una transparencia, sino más bien el resultado de pujas contingentes que la han definido de modos específicos y siempre pasibles de ser transformadas. En este sentido, seguimos al sociólogo Sergio Tonkonoff, quien plantea que la definición de violencia es relativa a un contexto socio-histórico, desligándola de un contenido específico a priori, ya que

[...] su realidad no es física sino paradójicamente simbólica, depende del sistema de clasificaciones morales vigentes en un tiempo y lugar dados. Pero esto implica entonces que esta definición se produce en el marco de disputas que son propiamente políticas. Ella tiene lugar, como cualquier otra definición que organice el campo social, en el seno de las luchas de interpretaciones llevadas adelante por las diversas prácticas sociales que producen ese contexto y son producidas por él (Tonkonoff, 2014:21).

Desde las formulaciones de Roger Silverstone, podemos problematizar el lugar de los medios masivos de comunicación en el marco de las mencionadas disputas en tanto que en las sociedades contemporáneas

[...] proporcionan con mayor o menor grado de coherencia los marcos de referencia (o los mundos de referencia) para la aparición del otro, definen de facto el espacio moral en el cual el otro se nos aparece y, al mismo tiempo, provocan (reclaman, delimitan) una respuesta moral equivalente en nosotros, la audiencia, en calidad de ciudadanos reales o potenciales (Silverstone, 2010:22).

Nos encontramos frente a la relevancia de los universos simbólicos, universos creados (no solamente) por los medios masivos de comunicación. Si bien los medios masivos crean relatos, quizá no sea allí donde resida su potencia, sino más bien en la posibilidad de ordenar, con mucha mayor eficacia que otros dispositivos, la totalidad de los relatos. Los medios masivos crean, pero también ordenan, jerarquizan, ocultan, iluminan, distorsionan e, incluso, eventualmente, informan. Es por eso que hablamos de configuraciones mediáticas, entramados complejos de sentidos que tensan con la experiencia cotidiana de quienes se apropian de sus contenidos.

Si bien entendemos que es en el momento de la apropiación, los usos o consumos de los bienes u objetos culturales (entre estos, los mensajes mediáticos) donde se efectiviza 
y produce el sentido, con consecuencias de comportamiento, perceptuales, cognitivas, emocionales, ideológicas muy complejas (Hall, 1980), también asumimos que relatos ajenos a la propia experiencia, sean o no ciertos, pueden ser vividos como verdaderos. Y en este sentido, la desigual distribución de poder entre individuos y conglomerados mediáticos (oligopólicos y transnacionales) tiene un marcado efecto sobre el ejercicio de las ciudadanías, ya que estos grandes organizadores de relatos, habitados por proyectos políticos bien definidos (y nunca en pos de las mayorías) terminan organizando, al fin de cuentas, la agenda pública, en tanto operan un cierto control y dominio en la selección de los contenidos y su tratamiento (Salazar Echeagaray, 2011).

En esta clave, asumimos como punto de partida que los medios masivos de comunicación se han convertido en un espacio privilegiado para la constitución del orden social y la construcción de hegemonías, siendo hoy uno de los principales dispositivos de autoridad que regulan lo legítimo e ilegítimo en nuestra sociedad, al establecer fronteras en los social que delimitan sujetos, zonas y prácticas aceptables y desechables. En consonancia con un ordenamiento social desigual y excluyente, los medios ejercen una violencia simbólica (Bourdieu, 1999) que establece jerarquizaciones, solapamientos, estigmatizaciones. De este modo, consideramos pertinente comprender estas narrativas como una violencia específica y no solo como la representación de otras violencias. Es así que, en consonancia con el marco normativo vigente en la República Argentina, adherimos al uso del concepto de "violencia mediática" y consideramos de vital importancia el despliegue de políticas culturales orientadas a combatirla.

Aunque distintas instituciones y organizaciones de derechos humanos ya lo venían sosteniendo con anterioridad, la Convención sobre la Eliminación de todas las formas de Discriminación contra la Mujer (CEDAW, por sus siglas en inglés), aprobada en 1979, fue un punto de inflexión en la materia, al precisar que la violencia contra la mujer constituye un tipo específico de violencia y que los Estados que adhieren a esta Convención asumen el compromiso de combatirla y de pugnar por la igualdad entre hombres y mujeres en su país. En Argentina, la CEDAW adquirió rango constitucional a partir de la última reforma de la Carta Magna, en el año 1994. Posteriormente, la Convención Interamericana para prevenir, sancionar y erradicar la violencia contra la mujer (conocida como Convención de Belém do Pará), ratificada por nuestro país en 1996, precisó la violencia contra la mujer como "cualquier acción o conducta, basada en su género, que cause muerte, daño o sufrimiento físico, sexual o psicológico de la mujer, tanto en el ámbito público como privado". Asimismo, este documento estableció con claridad que los discursos que estereotipan y discriminan a la mujer impiden el compromiso asumido por los Estados parte a pugnar por la igualdad entre hombres y mujeres, por lo que su accionar debe ir, asimismo, dirigido a combatirlos.

Unos años más tarde, al examinar el sexto informe periódico de la República Argentina con el fin de observar la adecuación del Estado a los principios establecidos en la CEDAW, el Comité para la Eliminación de la Discriminación contra la Mujer estableció entre las "principales preocupaciones" 
[...] la persistencia de estereotipos tradicionales relativos a las funciones y responsabilidades de las mujeres y los hombres en la familia y la sociedad, lo que representa un impedimento considerable para la aplicación de la Convención y constituye un grave obstáculo para que las mujeres gocen de sus derechos humanos. Además, el Comité está profundamente preocupado porque, como reconoció la delegación, algunos grupos de mujeres, además de ser objeto de estereotipos de género, afrontan múltiples formas de discriminación y violencia por motivos de orientación sexual e identidad de género, entre otros. En ese sentido, el Comité observa que los medios de difusión en el Estado parte refuerzan la imagen de las mujeres como objetos sexuales (CEDAW, 2010; cursivas nuestras).

En consonancia con estos tratados internacionales, y en función de la persistencia de la problemática en el país, en 2009 se sancionó la Ley 26.485 de protección integral para prevenir, sancionar y erradicar la violencia contra las mujeres en los ámbitos en que desarrollen sus relaciones interpersonales, que en su artículo 6. ${ }^{\circ}$, al especificar las modalidades de violencia, se plantea entre otras la "violencia mediática contra las mujeres", la cual es definida como

[...] aquella publicación o difusión de mensajes e imágenes estereotipados a través de cualquier medio masivo de comunicación, que de manera directa o indirecta promueva la explotación de mujeres o sus imágenes, injurie, difame, discrimine, deshonre, humille o atente contra la dignidad de las mujeres, como así también la utilización de mujeres, adolescentes y niñas en mensajes e imágenes pornográficas, legitimando la desigualdad de trato o construya patrones socioculturales reproductores de la desigualdad o generadores de violencia contra las mujeres.

Asimismo, esta ley establece, en su artículo $7 .^{\circ}$, que todos los poderes del Estado tienen el deber de hacer cumplir "el respeto irrestricto del derecho constitucional a la igualdad entre mujeres y varones". Por otra parte, la norma estipula líneas de acción para las diferentes áreas de Gobierno, entre ellas la Secretaría de Medios de Comunicación de la Nación, a la que insta a

a) Impulsar desde el Sistema Nacional de Medios la difusión de mensajes y campañas permanentes de sensibilización y concientización dirigida a la población en general y en particular a las mujeres sobre el derecho de las mismas a vivir una vida libre de violencias;

b) Promover en los medios masivos de comunicación el respeto por los derechos humanos de las mujeres y el tratamiento de la violencia desde la perspectiva de género;

c) Brindar capacitación a profesionales de los medios masivos de comunicación en violencia contra las mujeres;

d) Alentar la eliminación del sexismo en la información;

e) Promover, como un tema de responsabilidad social empresaria, la difusión de campañas publicitarias para prevenir y erradicar la violencia contra las mujeres. 
Por otro lado, también en 2009 fue aprobada en Argentina la Ley 26.522 de Servicios de comunicación audiovisual, que en su artículo 3. ${ }^{\circ}$ establece el propósito de promover la igualdad entre hombres y mujeres y evitar toda discriminación por género u orientación sexual. Asimismo, en esta norma se habla expresamente de la responsabilidad de los medios de comunicación de hacer cumplir la Ley 26.485 (de protección integral a las mujeres) en la totalidad de sus mensajes, incluyendo las publicidades, así como cualquier otro contenido emitido en ellos.

Por otra parte, esta ley dio surgimiento a la Defensoría del Público de Servicios de Comunicación Audiovisual, órgano que ha desempañado un rol fundamental en la lucha contra las narrativas mediáticas sexistas a partir de la intervención por iniciativa propia o ante denuncias realizadas por las audiencias que consideraron que algún contenido vulneró sus derechos o los de terceros. Asimismo, la Defensoría realiza campañas de difusión, dicta cursos de capacitación y realiza y divulga investigaciones propias en las que procura sensibilizar a la población en torno a sus derechos y sus eventuales vulneraciones por parte de algunos productos comunicacionales. Por otra parte, en diálogo con distintos actores y organizaciones sociales, el organismo elaboró la Guía para el tratamiento periodístico responsable de casos de violencia contra las mujeres ${ }^{3}$, así como la Guía para el tratamiento periodístico responsable de identidades de géneros, orientación sexual e intersexualidad ${ }^{4}$. En los primeros años de funcionamiento (2012-2016), la Defensoría recibió 9396 presentaciones, dictó capacitaciones a más de 70.000 personas y llevó adelante una monitorización de más de 500 horas de medios audiovisuales, lo que da cuenta de un rol protagónico en la defensa de los derechos de las audiencias. En la actualidad, el organismo se encuentra acéfalo producto de que la Comisión Bicameral pertinente aún no inició el procedimiento previsto por la ley con el fin de renovar su conducción, en el marco de una serie de profundas transformaciones y ataques del actual Gobierno nacional tanto a dicha ley como a los organismos que esta creó ${ }^{\text {. }}$

\section{Resultados}

Habiendo hecho una síntesis del marco legal que ampara el derecho a la igualdad entre hombres y mujeres en Argentina y que pone en primer plano la relevancia de los discursos mediáticos en dicho propósito, a continuación ofreceremos un análisis de las narrativas sobre violencia hacia las mujeres en los cuatro diarios antes mencionados. Los resultados de este análisis se presentarán en tres apartados a fin de dar cuenta, en primer lugar, de

\footnotetext{
3 Disponible en http://www.defensadelpublico.gob.ar/guia-para-el-tratamiento-periodistico-responsable-de-casos-deviolencia-contra-las-mujeres/

4 Disponible en http://www.defensadelpublico.gob.ar/guia-para-el-tratamiento-periodistico-responsable-deidentidades-de-generos-orientacion-sexual-e-intersexualidad/

5 La Ley 26.522 de Servicios de comunicación audiovisual fue uno de los principales enclaves de tensión entre el anterior gobierno de Cristina Fernández de Kirchner y los principales grupos económicos ligados al poder mediático, los cuales contribuyeron a horadar la legitimidad del "kirchnerismo" y a apuntalar la candidatura del actual presidente, Mauricio Macri, quien a pocos días de asumir modificó por decreto aspectos centrales de esta norma, sobre todo en lo concerniente a la regulación de la concentración mediática y a la participación de la ciudadanía en el control y la gestión de medios.
} 
una indagación general en torno a los meses relevados y, luego, el anclaje en dos casos que tuvieron amplia cobertura: "el caso de Micaela" y el "escándalo" entre Fede Bal y Barbie Vélez.

\section{La violencia de género en las narrativas mediáticas: primeras aproximaciones analíticas}

Un primer dato que podemos aportar al análisis de las noticias que forman nuestro corpus de trabajo es que el $40 \%$ de ellas se ubica en las secciones policiales de los diarios, dando cuenta de una lógica de producción periodística que funde estas violencias en las narrativas referidas al "delito común". Aun cuando en algunos casos se utilice el término "feminicidio" o incluso el de "violencia de género", en detrimento del antes usado "crimen pasional", su marco de comprensión no se desplaza de las fórmulas tradicionales de la prensa "roja": personas violentas que, por alguna motivación personal, cometen un hecho que se muestra como irracional e incomprensible. Cabe aquí establecer una distinción con el diario Página 12 que, además de no poseer una sección policial, tiene una larga trayectoria en la cobertura de las violencias contra las mujeres, tanto en el cuerpo principal del periódico como en algunos suplementos especializados, como Las 12 -específicamente feminista-y Soy -con perspectiva de género y diversidad sexual-.

Asimismo, podemos agregar que apenas el 1\% de ellas (seis artículos) se clasifica dentro del género "notas de opinión". Este dato habilita a pensar que las rutinas de producción periodística parecen estar más bien orientadas al incremento cuantitativo de la cobertura de estas violencias que hacia un ejercicio de reflexividad y comprensión de las estructuras simbólicas que las posibilitan y favorecen. Sumado a esto, vemos que tres de las seis notas de opinión relevadas fueron publicadas alrededor del "Día Internacional de la mujer" (8 de marzo) y otras dos en torno a la multitudinaria marcha "Ni Una Menos"6 (3 de junio), lo que nos advierte que estos trabajos de índole reflexiva obedecen menos a la consideración de la importancia de modificar conductas y hábitos que a la puesta en acto de lógicas de producción periodística que estipulan formas pre-moldeadas y a-críticas de referirse a ciertos tópicos en fechas determinadas. Entonces, el empleo de algunas nociones propias de las demandas del feminismo se diluye en la nota efeméride, que las funde sin perturbarse en frases de sentido común y expresiones políticamente correctas que no permiten reconstruir sus condiciones de posibilidad. Podemos incorporar, en este momento, un ejemplo para analizar esta perspectiva:

Los victimarios son cavernícolas: hombres que someten, que se imponen por la fuerza, que esclavizan mujeres como si ellas fueran un botín o una propiedad. En el medio está la sociedad y el Estado. En el medio estamos sin

\footnotetext{
Ni Una Menos fue el nombre que adoptó una de las mayores expresiones de la lucha que busca erradicar las violencias de género en Argentina. Consistió en una movilización al Congreso de la Nación -que se vio replicada en distintas ciudades del país-, el 3 de junio de 2015, reiterándose también en 2016 de manera masiva. Estaba organizada, en principio, por un grupo de periodistas, activistas, artistas, pero creció cuando amplios sectores de la sociedad la hizo suya y la convirtió en una campaña colectiva. Se sumaron organizaciones no gubernamentales, escuelas, partidos políticos, militantes y miles de personas al reclamo de frenar la violencia machista.
} 
las herramientas y las voluntades capaces de dejar en el pasado esta sistemática práctica de asesinatos y abusos (Clarín, 7 de marzo de 2016: s. / p.).

En este breve pasaje de un editorial, con motivo del Día Internacional de la Mujer, podemos observar cómo se articulan, no sin tensión, dos sentidos con respecto a las violencias de género. Por un lado, el señalamiento de que los feminicidios se fundan en el hecho de que los hombres se consideran con potestad sobre los cuerpos y las vidas de las mujeres ("como si ellas fueran un botín o una propiedad") y, por otro, la idea de sentido común que escinde estas prácticas de la sociedad que las posibilita ("Los victimarios son cavernícolas", "En el medio está la sociedad y el Estado", "En el medio estamos sin las herramientas y las voluntades"). Si sumamos a este fragmento la idea que se incluye al final del texto en torno a las violencias hacia las mujeres como "una enfermedad profunda", evidenciamos que no aparecen señaladas las estructuras socio-simbólicas que producen estas violencias, perdiéndose así la densidad política necesaria para el abordaje de esta problemática.

En esta línea, la inclusión de la noción de "feminicidio" en las notas analizadas suele utilizarse solamente como especificación de las víctimas del homicidio narrado y se la escribe, por lo general, entre comillas, citando las palabras de movimientos sociales, funcionarios políticos y causas penales, y no así como parte de la voz periodística. El uso que se hace de este término, además, ayuda a reforzar la asociación entre violencia de género y violencia física en tanto es la única forma de violencia que toma carácter público para convertirse en "un caso más", desatendiendo los procesos integrales de violencia simbólica, económica e institucional que constituyen la trama cultural y patriarcal. La sumatoria de casos aislados se inscribe, así, en la lógica narrativa que estos medios de comunicación emplean sin historizar ni relacionar de modo complejo estos sucesos.

Hasta aquí vemos que la inclusión de algunos términos de las agendas del feminismo no implica, necesariamente, un abordaje con perspectiva de género ni un tratamiento reflexivo en torno a las violencias machistas por parte de las narrativas mediáticas. Este punto se acentúa si tenemos en cuenta las construcciones de sentido que se realizan con respecto a las víctimas y los victimarios. En varias de las notas que forman parte de nuestro corpus de trabajo notamos que se construye al victimario como una persona "perversa", "irracional", "salvaje", "animal", "psicópata". Esto puede verse, por ejemplo, en las noticias en torno al feminicidio de Araceli Ramos ocurrido en el 20137. El diario La Nación, en una de sus notas, toma las declaraciones de un abogado diciendo que el acusado "Vinader fue un cazador salvaje, un perverso que salió a buscar a su víctima y el destino hizo que le tocara a Araceli Ramos" (La Nación, 3 de mayo de 2016: s. / p.). Podemos preguntarnos qué representaciones emergen cuando se le sacan las características "humanas" a los feminicidas y se los nombra como "animales salvajes" o se los patologiza como "enfermos

\footnotetext{
Araceli Ramos tenía 19 años y vivía en Loma Hermosa, al sur de la Provincia de Buenos Aires. Desapareció luego de haber concurrido a una entrevista laboral, que resultó ser falsa, el 30 de septiembre de 2013. Días después, su cuerpo fue hallado dentro de varias bolsas de residuos. Por el hecho, está condenado a cadena perpetua un ex prefecto, Walter Vinader, quien habría cometido el femicidio para vengarse de su ex mujer y de los policías que lo habían detenido años atrás.
} 
perversos". Estas narrativas insisten, de este modo, en aislarlos de la matriz cultural que los habilitan y los sostienen.

En estos abordajes observamos, además, que el diacrítico de género se articula estratégicamente con un enfoque xenófobo, reforzando estigmas que fracturan el continuum social a partir de la nacionalidad. El señalamiento de la "extranjeridad" de los hombres acusados de cometer abusos opera una invisibilización de la trama cultural patriarcal en la que esos "ataques" fueron cometidos, desplazando la atención hacia otros países, en general limítrofes de Argentina, pasibles de ser comprendidos como más violentos y machistas. Esta construcción de los victimarios se evidencia en la nota titulada "Cayó un hombre acusado de abusar a una menor en Los Hornos", publicada el por el diario El Día. En ella, se plantea que "un paraguayo de 65 años fue detenido en las últimas horas por personal de la DDI local acusado de haber abusado sexualmente a una menor que padece retraso madurativo" (El Día, 3 de mayo de 2016: s/p) Algo similar puede advertirse en el artículo "Golpeó a una chica y quiso entrar a su casa: lo detuvieron", en el que se señala que el acusado "según se informó se trata de un hombre mayor de edad de nacionalidad colombiana" (Clarín, 6 de mayo de 2016: s. / p.).

En línea con lo antes dicho, se construye la figura de la víctima desde dos posiciones diferenciales aunque complementarias. Por un lado, notamos la presencia de un régimen de representación de aquellas mujeres que fueron víctimas de feminicidios y, por otro lado, una formación distinta para las mujeres que fueron violentadas sexualmente, víctimas de acoso callejero o sufrieron violencia familiar y/o doméstica sin que sus agresores hayan "llegado a matarlas".

En el caso de los femicidios, los diarios analizados tienden a narrar los "asesinatos" retomando los avances judiciales y las carátulas de los expedientes policiales. Para ello, toman como fuentes principales a abogados, supuestos expertos del caso (tomado en forma aislada), fuerzas policiales y testimonios de los/as familiares de las víctimas. En este contexto, posee mayor gravitación la descripción de los "cuerpos" (violados, mutilados, enterrados o tirados en bolsas de residuos), así como de las modalidades específicas de estos hechos puntuales. En uno de los casos de feminicidio que más abordaron los medios de comunicación durante el año 2016, conocido como "el crimen de las mochileras mendocinas en Ecuador"8, se describe

La autopsia confirmó que presentaba muchos golpes en la cabeza provocados con un elemento contundente, un hematoma en una pierna, un dedo en el pie quebrado y marcas en las manos como signos de defensa. El cuerpo de Marina Menegazzo tenía un puntazo en el cuello que le rompió la médula y le causó la muerte casi en el acto, aunque también recibió varios golpes en el cráneo (Clarín, 30 de marzo de 2016).

\footnotetext{
8 María José Coni tenía 22 años y Mariana Menegazzo, 21. Vivían en Mendoza y viajaron a Ecuador de vacaciones. Luego de que sus padres denunciaran la desaparición de las dos amigas, fueron encontradas muertas el 28 de febrero de 2016 en la ciudad ecuatoriana de Montañita. La investigación comprobó que fueron drogadas primero para luego poder violarlas y matarlas.
} 
La narración de los cuerpos desde el discurso médico abona a la construcción de una hipérbole que teje una descripción morbosa y espectacularizada de su condición, a la vez que se pierde de vista su emplazamiento en el entramado social y cultural.

En cuanto a las mujeres que fueron víctimas de violaciones, acoso callejero o, como algunos medios los llaman, de "ataques sexuales", las narrativas mediáticas continúan privilegiando las voces de los funcionarios judiciales o policiales por sobre la de las propias víctimas para contar lo ocurrido. En este sentido, podemos citar la nota "Una estudiante volvía de la facultad, la sorprendieron en la calle y la violaron", en la que se afirma:

Según dijeron ayer a Clarín fuentes de la investigación, luego de ser liberada y una vez que pudo regresar a su casa caminando, la chica logró contarle todo lo que le había pasado a su madre (Clarín, 12 de mayo de 2016).

Por lo dicho hasta aquí, vemos que la mera incorporación a las agendas periodísticas de estas violencias no parece suficiente para comprender y transformar el problema. Ahora bien, estas tensiones ponen en escena una discusión más amplia que se relaciona con la violencia machista y la subordinación de las mujeres por su condición sexo-genérica. Es nuestra intención ahora poder reflexionar en relación con los modos en que se nombran y abordan las violencias de géneros por parte de las narrativas mediáticas, en un contexto en que se ha visibilizado y legitimado la lucha en contra de estas violencias en el conjunto amplio de la sociedad, a través del análisis de dos casos que obtuvieron gran relevancia en el tratamiento mediático de nuestro país.

\section{Re-victimización y control de la víctima. El "crimen de Micaela”}

Micaela Ortega tenía 12 años cuando, después de un mes de estar desaparecida, la encontraron muerta en Bahía Blanca el sábado 28 de mayo de 2016. La hallaron en un descampado a siete kilómetros de esa ciudad del sur de la provincia de Buenos Aires tras haber podido acceder a su cuenta de Facebook para conocer sus últimas conversaciones. La investigación policial y judicial comprobó que Jonathan Luna, un joven de 26 años que estaba prófugo desde 2014, creaba perfiles falsos en la red social para contactarse con mujeres, muchas de ellas menores de edad. Es así que se presentaba como una joven más y entablaba un diálogo que, en el caso de Micaela, se había dado desde febrero de ese mismo año. En la última conversación que tuvieron, Luna la invitó a Micaela a su casa en el barrio Saladero, cercano a la localidad Ingeniero White, y le dijo que la pasaría a buscar un primo de ella, que sería él mismo.

El hecho trascendió en los medios de comunicación nacionales el 29 de abril cuando, a una semana de la desaparición de Micaela, se organizó una marcha en Bahía Blanca pidiendo por su aparición. El diario Clarín fue quien abordó el caso en una nota titulada "Bahía Blanca: marcharán por una nena de 12 años que falta de su casa desde hace una semana". En ella, se califica a la búsqueda como "desesperado operativo" y se hace hincapié en la voz de la madre de Micaela, quien recuerda haber tenido una discusión con su hija el día previo a que se fuera de su casa por los usos que hacía de las redes sociales virtuales. Según su 
madre, buscaba "ponerle límites" a la adolescente que tenía muchos amigos en Facebook y aseguraba que le "cuesta creer que con 12 años haga estas cosas".

En esta línea, los comentarios de los lectores de la versión digital de esta nota están orientados a condenar las prácticas de crianza de los padres de Micaela así como también una supuesta actitud desafiante de la joven que justificaría su desaparición y la mostraría como "esperable". Podemos citar algunos comentarios que aseguran:

Si no disciplinas a tus hijos desde el vientre, mala suerte se augura. Desde los 80 veo cómo los padres quieren que todo sea fácil, Ligth.

Así no se educa.

La educación moderna donde los padres son amigos es un gran error falta autoridad y diálogo en las familias, para los padres que la nena ande pintada y venga a las 6 de la mañana de la jodita es pintoresco.

Advertir no es suficiente, se llama poner límites, algo que los padres modernos se niegan a hacer.

En estos comentarios, podemos encontrar algunos sentidos que se construyen en relación con la figura de los padres como disciplinadores de las prácticas de sus hijos, en donde "los límites" y "la autoridad" son principios fundamentales de la crianza. En este sentido, los padres "de ahora" no serían los mismos que los "de antes" porque no ponen límites en la crianza y, como consecuencia de ello, sus hijos son rebeldes a tal punto que se torna esperable que sus destinos sean "la jodita", "la mala suerte" e, incluso, la desaparición de su hogar.

Desde otra perspectiva, algunos lectores responsabilizaron a Micaela por su desaparición en tanto le adjudicaban ser "flor de trolita" y "una pendeja que está encamada y vuelve con la cocina llena de humo". Si bien al momento de publicarse esta nota y de haberse escrito estos comentarios no se había encontrado a Micaela asesinada, por lo cual no podemos asegurar que estén justificando su feminicidio, ilustran la existencia de potentes configuraciones de sentido que apuntan a responsabilizar la desaparición de una adolescente de 12 años a partir de determinadas prácticas que no se ajustarían con un deber ser padre, madre o joven, de acuerdo con el testimonio que tomemos.

Por su parte, Página 12 publicó una nota al cumplirse un mes de la desaparición de Micaela, en la que se desarrollan las hipótesis que se estaban analizando en la investigación, y recupera como fuente principal la voz de su madre. Tal como lo había manifestado antes, ella le adjudicaba la responsabilidad de la situación al uso que hacía Micaela de las redes sociales: tener varios perfiles de Facebook y más de 500 amigos era "peligroso", por lo cual aseguraba que su hija había sido "víctima de las redes sociales". De este modo, este feminicidio hizo emerger, asimismo, algunos discursos que no pusieron el foco en la persona que la mató o que la secuestró de acuerdo a lo que se hipotetizaba en ese momento -solo se conocía un vídeo de una cámara de seguridad en la que se veía a Micaela caminando con un hombre--, sino, en este caso, en las redes sociales y su supuesta peligrosidad. 
Esta formación discursiva -que excedió al propio entorno familiar- hizo énfasis en la necesidad de reforzar el control por parte de los adultos del uso de las redes sociales que hacen los jóvenes, en la medida en que se lo consideró un ámbito especialmente hostil, por cuanto los peligros que acecharían a cada instante son difíciles de advertir para quien no cuenta con la suficiente madurez. Es un enfoque que, en palabras de la investigadora Roxana Morduchowicz, "propone una imagen de los jóvenes como víctimas inocentes y completamente vulnerables" (2008:12) y, entonces, como pasivos, vacíos, manipulables y sin historia. No hubo una reflexión acerca de las apropiaciones que ellos realizan, sino más bien se buscó comprender y legitimar el sentido de una desaparición, y luego un feminicidio, desde una óptica adultocéntrica, tecnofóbica y apocalíptica.

Las próximas notas publicadas con respecto al "caso" son del 29 de mayo, el día pos terior a haberse encontrado a Micaela muerta. Esta noticia pasa de ubicarse en la sección "Interés general" a "Policiales" en el caso de Clarín y El Día. A diferencia de estos medios, Página 12 la posiciona siempre en la sección "Sociedad" (recordemos que este diario no tiene sección "Policiales") y La Nación vincula las noticias con dos etiquetas: "Seguridad" y "Violencia de género". Estas notas se extienden hasta el 2 de junio, ocupando lugar en los diarios analizados durante cuatro días. A diferencia de otros tratamientos en torno a feminicidios cuya duración en agenda es más amplia, extendiéndose incluso a meses, este caso fue abordado en los días inmediatos al conocimiento del hecho y en los que se resolvió la causa. Tal como mencionamos en el apartado anterior, se trata de una lógica de noticiabilidad recurrente que consiste en ligar la cobertura de feminicidios al devenir en los espacios judiciales y policiales.

Por su parte, estas primeras notas publicadas apuntan a dar detalles en torno a la aparición del cuerpo y al modo en que habría sido asesinada Micaela a partir de los datos que arroja la autopsia y el expediente judicial. Una vez más, la mujer asesinada deviene en un cuerpo medicalizado y judicializado del que se borran las huellas de la violencia machista y patriarcal que lo posibilitó. En este sentido, Clarín titula "Engañó a una nena por Facebook y la estranguló" (30 de mayo de 2016: s/p) y "La autopsia revela que Micaela murió estrangulada" (29 de mayo de 2016: s/p), jerarquizando el modo en que habría sido asesinada la joven en un gesto que termina espectacularizando el tratamiento del hecho antes que abordarlo reflexivamente.

Otro notas publicadas ponen el foco en Jonathan Luna, el asesino de Micaela. Se destaca que estaba prófugo desde hacía dos años y que creaba perfiles falsos en Facebook para comunicarse con mujeres jóvenes. Así, por ejemplo, se intenta reconstruir un perfil del detenido destacando su "prontuario" y sus "antecedentes penales". El Día titula "El pesado prontuario del sospechoso" (30 de mayo de 2016: s/p) y Clarín, "¿Quién es el joven que confesó haber matado a Micaela?" (Ídem). Estas notas presentan a Luna como "prófugo", "condenado de la justicia" y "convicto", creando una línea de continuidad entre sus antecedentes por robo calificado y el asesinato de Micaela como si estuvieran en posiciones equivalentes. 
A propósito de la construcción de la figura del victimario, en los comentarios que los lectores comparten, se pide su pena de muerte a la vez que se plantea esta medida como una solución preventiva ante nuevos posibles feminicidios. En esa línea, el asesino es calificado como "monstruo", "bestia", "basura", "degenerado", "psicópata", "salvaje", e incluso se menciona que no debe ser nombrado como "joven" tal como lo hace el diario porque no merece esa condición, sino la de "hijo de puta". Vemos, entonces, que se le quita su condición humana, se lo patologiza y se vuelven a desdibujar las condiciones de posibilidad que sostienen su práctica.

Asimismo, cuando los lectores opinan al respecto aseguran que la culpa del feminicidio fue, por un lado, de los padres por no controlar a su hija y, por otro, de Micaela por usar Facebook. Algunos de los comentarios publicados son:

Los padres tienen que volver a ser padres- eso del padre piola, padre compinche es una boludez. Lo mismo que los chicos y menores usen celulares y redes sociales!!", "Papis: SAOUEN A LOS NENES DE FACEBOOK. Creen que les están haciendo un bien? Al contrario, los están enchufando, idiotizando y encima los ponen en peligro", "Cuando decimos ni una menos las chicas deben ayudar, y los padres controlar!!!! Tenía 12 años, (no cinco) y si tenía Internet sabía de las desapariciones de las chicas!!!", "Un chico o chica de 13 años, no tiene por qué tener un face con un montón de desconocidos, es más, no tendrían que tener face", "Los padres de esta chica, que hacían en lugar de cuidarla??????????????", "¿y la madre? ¿Dónde estaba la madre?", "Por qué Micaela tenía 4 cuentas?".

De acuerdo con estos argumentos, son los padres los que tienen que controlar, y las mujeres las que tienen que cuidarse de no ser asesinadas. Por qué los hombres matan a las mujeres y por qué se ejerce violencia de género no son interrogantes válidos en este marco de entendimiento. La necesidad de implementar políticas públicas que tiendan a problematizar y prevenir la violencia de género también es sacada del foco para, en cambio, responsabilizar a las mujeres, los padres (sobre todo a la madre) y las redes sociales. Este argumento se combina con un discurso adultocrático en donde los adultos son quienes tienen la capacidad de orientar, alumbrar, guiar, ser faros de jóvenes que no tienen las herramientas para hacerse cargo de sus vidas. Se ve a los jóvenes como sujetos "en espera" para ser: serán cuando alcancen la adultez, y, por tanto, se los nomina desde la falta, la carencia, la negación. (Chaves: 2005).

Por otro lado, el hecho es nombrado por los medios de comunicación analizados como "el crimen de Micaela", "asesinato", "homicidio" y solo en dos notas como "feminicidio". En este sentido, la condición de género de Micaela no adquiere preponderancia en el tratamiento y se desdibuja la violencia de género como modalidad constitutiva del hecho. Si bien, como mencionamos anteriormente, el diario La nación incluye la etiqueta "Violencia de género" para vincular todas las notas referidas al caso, el marco conceptual empleado sigue anclado en las formaciones discursivas tradicionales que ocultan la desigualdad sexo-genérica como condición de posibilidad. De este modo, a pesar de la inclusión de esa etiqueta para nombrarlo, el asesinato de Micaela Ortega aparece como un hecho aislado y autónomo, y no aparece vinculado con otros casos previos. En cambio, se decide agregar adjetivos 
para calificar al hecho como: "aberrante asesinato", "un crimen que estremece", "brutal crimen", "trágico final", presentándolo de forma espectacularizada. Al mismo tiempo, a Micaela se la nombra, la mayoría de las veces, como "la chica de 12", la "niña", la "nena", la "chiquita", la "pequeña", "la víctima" y, en menor medida, como la "adolescente", la "joven" y la "menor". Estos modos de nombrarla, excepto el de víctima, se corresponden con su condición etaria que, a diferencia de su condición de género, sí es remarcada constantemente. A los fines de reforzar la espectacularización del caso, que sea una "niña" o una "chiquita", más que una "mujer" parecería convertir al crimen en más "aberrante" y, por lo tanto, noticiable.

La espectacularización que producen las narrativas mediáticas referidas a casos de violencia de género, entonces, constituyen uno de los principales rasgos que obturan la posibilidad de situar estos hechos dentro de una trama cultural machista, aun cuando es posible advertir la presencia de ciertas retóricas y modos de nombrar que provienen de las luchas feministas. Esta tendencia frivolizadora de demandas históricas del movimiento de mujeres aparece potenciada en la prensa vinculada al "mundo del espectáculo". Un caso notorio dentro del período aquí estudiado fue protagonizado por Federico Bal y Bárbara Vélez en el que nos detendremos a continuación

\section{El "escándalo" entre Fede Bal y Barbie Vélez (o la frivolización de un tema ineludible)}

Como dijimos anteriormente, la violencia machista se ha vuelto un asunto insoslayable en las narrativas mediáticas, y el modo en que el tratamiento periodístico suele incorporar el concepto merece una lectura atenta, capaz de desentrañar los sentidos que se le anudan y que acaso la domestican y la funden en el paisaje superfluo de la espectacularización. En este sentido, la cobertura mediática de la relación violenta entre Federico Bal y Bárbara Vélez nos aporta numerosos elementos para reflexionar al respecto. Comencemos por reponer la escena.

Desde que comenzaron a "salir", Barbie Vélez y Fede Bal se transformaron en una de las parejas preferidas por parte de las narrativas mediáticas dedicadas a la "farándula". Varios condimentos confluían en la determinación de esa "consagración". Por un lado, ambos son hijos de personas famosas pertenecientes al mismo universo semántico: la mamá de él, Carmen Barbieri, fue bailarina y vedete del "teatro de revista" y conductora de un reconocido programa televisivo de chimentos sobre el "mundo del espectáculo"; el papá de él, Santiago Bal, es un importante productor teatral; la mamá de ella, Nazarena Vélez, alcanzó fama por ser la pareja de Hernán Caire, reconocido conductor de un programa televisivo de música tropical, con quien se separó luego en malos términos -con acusaciones de maltratos incluidas-y siguieron manteniendo una relación conflictiva con amplia cobertura mediática; posteriormente, siguió teniendo una importante presencia en los medios, trabajando como actriz, productora y asistente de conducción. Por lo demás, Carmen Barbieri y Nazarena Vélez mantuvieron durante largo tiempo una disputa que las convirtió en "enemigas públicas". La relación de sus hijos, de enormes resonancias me- 
diáticas, aportaba un elemento dramático que los programas de espectáculos supieron interpretar y reforzar.

Por si esto fuera poco, la participación de la pareja en Bailando por un sueño, el programa de entretenimientos televisivo de mayor audiencia de la Argentina y del que se desprende un conjunto de programas satélites que lo amplifican indagando el "detrás de escena" -la previa a la competencia, el análisis de las performances, los supuestos romances y peleas entre los participantes- aumentó la tensión dramática, que difícilmente podía resolverse sin un "escándalo". En ese marco, la representación mediática del romance fue caracterizada por la desconfianza mutua y los celos: sus propios integrantes reconocían que se revisaban los celulares, las cuentas de Facebook, entre otras prácticas que iban pre-anunciando el desenlace conflictivo que todos preveían.

Finalmente, en abril de 2016, se desencadena el "escándalo", como pasarían a referirse desde entonces los medios al conflicto entre ambos. La "causa" fue la supuesta "infidelidad" que el joven habría cometido para con su pareja al mantener relaciones sexuales con una de las bailarinas del show televisivo del que ambos participaban. De inmediato, se hicieron públicas las peleas y las denuncias cruzadas entre ellos, lo que permitió el ingreso de un concepto ajeno a este género periodístico: violencia de género. "Barbie acusa a Fede de violencia de género", "¿violencia de género entre Fede y Barbie?", son algunos de los títulos que dan cuenta de ello.

Desde ese momento, la cobertura del conflicto se incrementa aún más. Ya no basta con el testimonio de los protagonistas: aparecen las voces de las madres, los padres y otros familiares; abogados de ambos; vecinos y supuestos testigos de los hechos de violencia entre ellos. La situación adquiere todavía un grado de mayor espectacularización al publicarse unas fotos tomadas a Barbie Vélez para la revista Gente, en las que se observan moretones en uno de sus brazos. La pregunta que nos interesa introducir aquí respecto de la orientación ideológica que conllevan las representaciones mediáticas de las conflictivas relaciones de pareja entre Fede Bal y Barbie Vélez. ¿Permiten visibilizar la problemática social que enuncian como "violencia de género"? ¿De qué modos la significan? ¿Qué marco de sentidos construyen como contexto específico y condición de posibilidad?

Un primer aspecto a tener en cuenta, en este sentido, es que estas representaciones, al mismo tiempo que ponen en escena una problemática social de enorme relevancia, operan una "frivolización" de ella, le restan espesor político al volverla un fenómeno del mundo del espectáculo, que da rating y visibilidad a quienes participan de estos relatos. La pregunta que comienza a ganar terreno a medida que se va extendiendo esta cobertura es si no se trata de una estrategia de los medios para "vender" sus productos comunicacionales y / o de los implicados para posicionarse y adquirir un protagonismo que podría redundar en una mejora de sus condiciones laborales y económicas. Se trata, en efecto, de una de las hipótesis recurrentes en los comentarios de los lectores en los medios relevados: "Creo que lo usan para promocionarse y victimizarse", "tienen que hacer algo para llamar la atención y tener cámara". En una línea similar, aunque no centrando la atención exclusivamente en los 
protagonistas del hecho, sino también en la responsabilidad de los medios, se encuentran algunos comentarios como el siguiente:

"Déjense de hablar del tema y de sumarse a NI UNA MENOS! No tienen vergüenza. Si les importara no estarían en los programas donde están, donde se ningunea, se burlan de las personas, no son ningún ejemplo sobre la representación que hacen de las mujeres, se escarba en las vidas personales y sus historias de cama, etc. Ahora hay que aguantar la farandulización y banalización por parte de ustedes de un tema tan grave.

Si bien podría pensarse que la frivolización y la "confusión" entre realidad y ficción forman parte de los modos de producción de las narrativas mediáticas sobre la "farándula", interesa poner de relieve la ausencia de coberturas que repongan el contexto de la violencia machista como marco en el que se producen los hechos narrados, con la excepción-dentro de nuestro corpus- de un artículo breve publicado el por Flor Monfort, titulado "Todo es igual" (Página 12, 13 de mayo: s/p), quien advierte el peligro de la espectacularización de una problemática que al mismo tiempo que gana espacio en las noticias no deja de expandirse y reproducirse en las prácticas sociales. El riesgo de este tipo de cobertura reside justamente en que funde la violencia de género en las aguas del mundo de las "rencillas mediáticas", donde todo se vuelve opinable y discutible. En este sentido, tienden a confundirse las implicancias judiciales con las valoraciones de las audiencias y otros "especialistas" ad hoc. En este sentido, varios medios preguntan a sus lectores a cuál de los implicados le asignan razón.

Es interesante detenerse en este punto por cuanto el "debate" que se suscita entre quienes consumen estos medios moviliza sentidos en disputa que merecen atención, disputa que de algún modo aparece organizada y moldeada por las propias narrativas mediáticas, que plantean un conflicto entre actores que de ningún modo parten de un lugar de igualdad, puesto que su relación se enmarca en tramas simbólicas caracterizadas por la violencia sistemática hacia las mujeres.

De todos modos, lo primero que debe decirse es que la lectura de los comentarios de los lectores de la versión digital de los medios relevados nos devuelve un paisaje de relativa heterogeneidad. No se trata de un universo homogéneo, sino más bien dotado de un carácter polémico, si bien sus términos y sus alcances, como decíamos, encuentran límites y condicionantes en las propias notas periodísticas.

Por un lado, en estrecha vinculación con quienes consideran que todo forma parte de un "circo mediático" al que no debe prestarse mayor atención, aparecen algunos testimonios que pretenden deslegitimar las denuncias realizadas por Bárbara Vélez enfatizando especialmente en su figura. Mientras varios comentarios ponen en primer plano su evidente afán de posicionarse en la escena mediática, otros remarcan un supuesto "desequilibrio" emocional. La llaman "loca", "loquita" y también "la psiquiátrica", muchas veces sin nombrarla. Algunas intervenciones incluyen a la madre en sus comentarios, también asignándole condiciones patológicas: "no olvidemos que la loca de la madre se hizo conocida por denunciar que Hernán Caire la maltrataba, y desde ahí está metida en todos los puteríos habidos y por 
haber", "eso es todo prensa para dar lástima y que la voten en el bailando. La loca de la madre es la libretista y le dice todo lo que tiene que hacer y decir".

Por otra parte, entre quienes deslegitiman la palabra de Barbie Vélez, se hallan algunas referencias a su propia responsabilidad en los hechos. Es interesante observar cómo algunos testimonios se van desplazando hacia la problemática de la violencia hacia las mujeres sin que las narrativas mediáticas pongan el énfasis allí. En este sentido, algunos lectores señalan que las mujeres deberían hacer las denuncias antes de que se llegue a situaciones de tanta gravedad. Otros se interrogan respecto del rol de "las madres" que "crían machitos violentos". Asimismo, hallamos algunos testimonios que dicen que también las mujeres ejercen violencia en muchos casos, por lo que habría que evitar la victimización.

Este tipo de comentarios es rebatido por otros lectores, quienes plantean que no se pueden igualar ambas situaciones. Uno de estos testimonios señala: "Me parece que igualar la situación de las mujeres con los hombres en cuanto a discriminación y maltrato basándose en algunos casos (...) es exagerar un poco". Por otra parte, algunas de las personas que comentan estas notas se focalizan en una crítica hacia las mujeres que justifican la violencia machista. Por ejemplo, una de ellas comenta:

Qué poca solidaridad con el género. Un tipo te puede violentar física, emocional y psicológicamente y la loquita es siempre la mujer. [...] Ella es una loquita, viene de una familia de loquitas, se viste como una loquita y está provocando, lo volvería loco [...] Nacer mujer en Argentina es un castigo.

Asimismo, hay quienes aprovechan el espacio para instar a otras mujeres a no aceptar la violencia de parte de sus parejas y algunos comentarios hacen referencia también a la dimensión pedagógica positiva que tiene la cobertura de este tema, como el siguiente: "Esto enseña que otras mujeres víctimas de actos de violencia deben denunciar".

De este modo, el "debate" planteado entre quienes comentan las noticias expande los sentidos al agregar algunos elementos que no aparecen puestos en primer plano en el tratamiento específico que realizan los medios del tema. En este sentido, se vuelve especialmente relevante la pregunta por la circulación de las significaciones en torno a estas violencias, aspecto que seguiremos trabajando en futuros trabajos en el marco de este mismo proyecto.

\section{Discusión de los resultados}

A lo largo de este trabajo intentamos analizar los modos en que aparece representada la violencia hacia las mujeres en cuatro medios gráficos de la República Argentina, procurando situar esos relatos en su contexto tanto normativo como socio-político específico. La importancia asignada a los mismos se basa tanto en la premisa que concibe a la sociedad como orden simbólico - esto es, discursivo-, como en la convicción de que en la actualidad los medios de comunicación juegan un rol central en el establecimiento de los parámetros que regulan lo social. En este sentido, el análisis de estas narrativas mediáticas nos arroja algunos elementos que interesa volver a poner de relieve en este apartado final. 
Por un lado, advertimos la persistencia de relatos que eluden toda consideración a los asesinatos sistemáticos de mujeres en términos de feminicidios. En estos casos, o bien se funden en las narrativas tradicionales de la "prensa roja" como casos de "inseguridad" sin especificidad alguna o bien se los agrupa bajo el prisma de "crímenes pasionales" -aún sin nombrarlos de este modo-, una concepción fuertemente rebatida por el feminismo pero aún recurrente en las lógicas de producción periodística.

Asimismo, advertimos que, en numerosas ocasiones, estos relatos incorporan términos como "feminicidio" o "violencia de género", sin que ello implique una reconceptualización de los hechos. En este sentido, el incremento cuantitativo de notas acerca de estas violencias como la utilización de estas nociones no ha logrado poner en primer plano los hilvanes que aglutinan estas violencias y que las vuelven parte de una misma trama de producción cultural. Del mismo modo, no se sitúa al homicidio en el marco de una relación de poder en la cual las identidades del victimario y la víctima se tensionan y ponen en juego, con la clara subordinación de la mujer por el hecho de ser mujer.

Estas noticias, en cambio, son proclives a ocultar el carácter sistemático de estas violencias, aún en los casos en los que agregan datos estadísticos, en la medida en que no las sitúan en las estructuras materiales y simbólicas que las producen. Esta escisión se expresa de manera ostensible cuando se patologiza al victimario o se lo muestra como presa de una supuesta emoción que lo saca de sí mismo. De este modo, la violencia se torna incomprensible o simplemente referida a un sujeto particular fuera de sus "cabales" y su base de apoyo socio-simbólica tiende a disiparse. Por otra parte, al hacerse un tratamiento morboso de las víctimas -sus cuerpos, sus prácticas- se las re-victimiza, asignándoles responsabilidad en lo ocurrido.

En este mismo sentido, observamos que en algunas notas se opera una articulación estratégica entre el diacrítico de género y otros como la generación, la clase o la nacionalidad. En todos los casos, se produce una "alteración" de las violencias, que se muestran ajenas a un supuesto estado de normalidad. Así, los discursos mediáticos analizados plantean prácticas de control que, en lugar de poner en cuestión el statu quo, lo reproducen.

Por otro lado, si bien observamos que existe una proliferación de notas que señalan las violencias por razones sexo-genéricas, lo que ilustra su plena inclusión en las agendas informativas, advertimos una tendencia a la reproducción de "casos" aislados, sin continuidad -salvo excepciones-y sin marcos reflexivos que permitan comprenderlos y evitarlos. Ilustrativo de ello es que apenas seis de las 525 notas relevadas sean de opinión. Al mismo tiempo, interesa destacar que en contextos de fuerte politización social como en el de la movilización Ni Una Menos, se produjo una modificación de estas narrativas, adquiriendo los feminicidios un tratamiento más adecuado, en la medida en que en algunas notas se los situó como parte de la trama cultural en la que se producen y no como hechos "alterizados". Es probable que ello se deba a la presión específica propagada por un conjunto de prácticas discursivas que pusieron el eje en el rol de los medios en la reproducción, ocultamiento y naturalización de estas violencias. Tal vez haya aquí un aspecto intere- 
sante para profundizar en futuros trabajos, en la medida en que puede contribuir a una reflexión acerca de los márgenes de acción táctica y estratégica para aquellos sectores comprometidos con la igualdad de género.

\section{Conclusiones}

Al mismo tiempo, y en función de la centralidad de las narrativas mediáticas en la constitución del orden social, se vuelve imperioso avanzar en una regulación estatal de las mismas que privilegie la igualdad entre los hombres y las mujeres por encima de las lógicas mercantilistas que imperan en la actualidad. Son precisas, por lo tanto, políticas de comunicación y cultura orientadas a reconocer la comunicación como derecho humano, más que como una mercancía, y a incorporar la perspectiva de género como dimensión fundamental para transformar el orden patriarcal.

La regulación de las telecomunicaciones constituye un problema de primer orden en las democracias latinoamericanas actuales y ha sido uno de los principales enclaves de conflicto entre los gobiernos progresistas ${ }^{9}$ de la región en los últimos años y los grupos de poder presentes en cada país (De Moraes, 2011).

Frente a las diferentes políticas impulsadas por estos gobiernos, es recurrente la manifestación de discursos que afirman que la regulación estatal de las telecomunicaciones hace peligrar la libertad de expresión, por lo que se propone que sea el "libre" juego del mercado comunicacional el que defina la oferta en función de los "gustos" de las audiencias. Además de soslayar problemas centrales a resolver, como las reglas precisas e históricamente constituidas tanto del pretendido libre juego del mercado comunicacional como de la construcción social del gusto, planteada de este modo la discusión se despliega en torno a un -a nuestro entender-falso dilema acerca de si regular o no el espectro mediático. Los medios de comunicación siempre tienen condiciones específicas (normas, reglas, posibilidades económicas y culturales, etc.) que delimitan su accionar. Las políticas (neo) liberales suelen presentarse a sí mismas como procesos de des-regulación, cuando en verdad constituyen un tipo de regulación específico proclive a la reproducción de un orden social injusto, que pone el interés de grupos particulares por encima del bienestar general. De ahí que autores como Guillermo Mastrini prefieran hablar de procesos de "re-regulación" (2009).

En el caso de la República Argentina, la mencionada Ley de Servicios de comunicación audiovisual, sancionada en el año 2009, vino a modificar una tendencia gestada durante décadas favorable a la concentración mediática y al establecimiento de la comunicación como una mercancía. Por el contrario, la nueva norma -impulsada por un amplio conjunto de organizaciones y sectores sociales- erigió a la comunicación en un derecho y en un servicio

\footnotetext{
$9 \quad$ Nos referimos a los gobiernos de Rafael Correa en Ecuador, Michelle Bachelet en Chile, Hugo Chávez y Nicolás Maduro en Venezuela, Lula da Silva y Dilma Rousseff en Brasil, Tabaré Vázquez y José Mujica en Uruguay, Evo Morales en Bolivia y Néstor Kirchner y Cristina Fernández en Argentina. Optamos por una caracterización amplia ("gobiernos progresistas") que permita integrar las diferentes experiencias, sin desconocer ni sus diferencias ni los distintos modos de referirse a ellas.
} 
público de primer orden. Esta ley impulsó la desconcentración de la estructura propietaria del sistema mediático y habilitó numerosos mecanismos para el establecimiento de una comunicación más democrática, plural e igualitaria. Como dijimos anteriormente, entre los aspectos principales que podemos mencionar en este sentido se encuentra la creación de la Defensoría del público de servicios de comunicación audiovisual, órgano encargado de defender integralmente los derechos de las audiencias.

A fines de 2015, pocos días después de asumir, el actual presidente, Mauricio Macri, mediante el Decreto 267/15 decidió "re-regular" el sistema de medios argentino, ampliando los márgenes de la concentración mediática y limitando la participación de los actores sociales que pugnan por desarrollar una comunicación no comercial y atenta, en cambio, a otras necesidades y demandas, lo cual constituye un fuerte retroceso para quienes bregamos por una sociedad más justa e igualitaria. Como puede verse en el análisis aquí efectuado, modificar el actual estado de cosas requiere de activas políticas de comunicación y cultura, no porque los medios sean la exclusiva fuente discursiva de donde emergen los trazos que dibujan el orden social, sino sencillamente porque los sentidos socialmente relevantes pasan a través de ellos, y allí son reorganizados, jerarquizados, propagados o solapados. Como señala Emiliano Sánchez Narvarte,

[...] el problema dejó de ser simplemente mediático para desplazarse al sistema de producción cultural, a los procesos de producción, circulación y recepción de bienes simbólicos y las formas socioculturales y político-económicas que se configuran (2015: s. /p.; cursivas en el original).

Ajenos a una perspectiva esencialista del orden social, no creemos en la existencia de una lógica inherente a la dinámica de los medios, que necesariamente los movilice a la vulneración de derechos. Por el contrario, consideramos que pueden erigirse -y en ocasiones lo hacen- en una herramienta fundamental para visibilizar y deconstruir distintos tipos de violencias, estereotipos y mandatos. El desafío es asumir su carácter de servicio público y encontrar las herramientas para garantizar que su funcionamiento propenda a la igualdad entre hombres y mujeres.

\section{Referencias bibliográficas}

Bourdieu, P. (1999) La miseria del mundo. Madrid: Akal.

Chaves, M. (2005) "Juventud negada y nagativizada: representaciones y formaciones discursivas vigentes en la Argentina contemporánea". En: Revista Última década Vol. 13. Num. 23. Santiago de Chile, Chile.

De Moraes, D. (2011) La cruzada de los medios en América Latina. Gobiernos progresistas y políticas de comunicación. Buenos Aires: Paidós.

Mastrini, G. (ed.) (2009) Mucho ruido, pocas leyes. Buenos Aires: La Crujía

Morduchowicz, R. (coord.) (2008). Los jóvenes y las pantallas. Nuevas formas de sociabilidad. Barcelona: Gedisa.

Sánchez, N. (2015) "Procesos de privatización y concentración mediática. Una introducción al problema". Ficha de cátedra para la materia Comunicación y Medios cátedra III de la Facultad de Periodismo y Comunicación Social, Universidad Nacional de La Plata. 


\section{Fuentes consultadas}

AA. W. (2015) "Ni una menos". Documento leído en la movilización al Congreso de la Nación el 3 de junio de 2015. [en línea]. Disponible en http://s1000050.ferozo.com/wp-content/uploads/2015/06/ documento_OK-1-1.pdf

Bourdieu, P. (1999). "La miseria del mundo". Madrid: Akal.

Chaves, M. (2005) "Juventud negada y nagativizada: representaciones y formaciones discursivas vigentes en la Argentina contemporánea". En Revista Última década Vol. 13. Num. 23. Santiago de Chile, Chile.

Convención Interamericana para prevenir, sancionar y erradicar la violencia contra la mujer (1994) [en línea] Disponible en https://www.oas.org/dil/esp/convencion_belem_do_para.pdf . Consultado En enero de 2016 5:00 p.m.

Convención sobre la eliminación de todas las formas de discriminación contra la mujer (1979). [en línea] Disponible en http://www.un.org/womenwatch/daw/cedaw/text/sconvention.htm

Delmas, F. (2014). "En los medios existe una pedagogía de la crueldad". Entrevista a Rita Segato. La Plata: Facultad de Periodismo y Comunicación Social. [en línea] Disponible en http://perio.unlp. edu.ar/node/4602

De Moraes, D. (2011) La cruzada de los medios en América Latina. Gobiernos progresistas y políticas de comunicación. Buenos Aires: Paidós.

Fernández, A. M. (2009). "Las lógicas sexuales: amor, política y violencias". Buenos Aires: Nueva Visión.

Grimson, A. (2011). Los límites de la cultura. Buenos Aires: Siglo XXI.

Guía para el tratamiento periodístico responsable de casos de violencia contra las mujeres (2016). Buenos Aires: Defensoría del público de servicios de comunicación audiovisual. [en líneal Disponible en http://www.defensadelpublico.gob.ar/wp-content/uploads/2016/10/guia_violencia_contra_mujeres_pdf. pdf Consultado En enero de 2016 5:00 p.m.

Guía para el tratamiento periodístico responsable de identidades de géneros, orientación sexual e intersexualidad (2016). Buenos Aires: Defensoría del público de servicios de comunicación audiovisual. [en línea] Disponible en: http://defensadelpublico.gob.ar/guia-para-el-tratamientoperiodistico-responsable-de-identidades-de-generos-orientacion-sexual-e-intersexualidad/ Consultado En enero de 2016 5:00 p.m.

Hall, S. (1980). Stuart Hall. Codificar / descodificar. En Culture, Media y Lenguaje. London: Hutchinson. Traducción: Silvia Delfino.

Kessler, G. (2009). El sentimiento de inseguridad. Buenos Aires: Siglo XXI.

Lagarde, M. (2008) "Antropología, feminismo y política: violencia feminicida y derechos humanos de las mujeres" En Actas del XI Congreso de Antropología. Retos teóricos y nuevas prácticas. Donostia, San Sebastián.

Ley 26.485 de protección integral para prevenir, sancionar y erradicar la violencia contra las mujeres en los ámbitos en que desarrollen sus relaciones interpersonales (2009). (en líneal Disponible en http:// servicios.infoleg.go6.ar/infolegInternet/anexos/150000-154999/152155/norma.htm Consultado En enero de 2016 5:00 p.m. 
Ley 26.522 de Servicios de comunicación audiovisual (2009). [en línea] Disponible en http://servicios.infoleg. gob.ar/infolegInternet/anexos/155000-159999/158649/norma.htm Consultado En enero de 2016 5:00 p.m.

Mastrini, G. (ed.) (2009) Mucho ruido, pocas leyes. Buenos Aires: La Crujía

Morduchowicz, R. (coord.) (2008). Los jóvenes y las pantallas. Nuevas formas de sociabilidad. Barcelona: Gedisa.

Observaciones finales del Comité para la Eliminación de la Discriminación contra la Mujer (2010). len línea] Disponible en http://www.acnur.org/t3/fileadmin/Documentos/BDL/2012/8408.pdf Consultado En enero de 2016 5:00 p.m.

Periodistas de Argentina por una comunicación no sexista (2008) "Decálogo para el tratamiento periodístico de la violencia contra las mujeres". (en líneal Disponible en http://www.artemisanoticias. com.ar/images/FotosNotas/Decalogo_PAR.pdf

Reguillo, R. (2006). "Los miedos, sus laberintos, sus monstruos, sus conjuros. Una lectura socio-antropológica" en Etnografías Contemporáneas. Año 2, N. ${ }^{\circ} 2$.

Saintout, F. (2013). Los jóvenes en la Argentina. Desde una epistemología de la esperanza. Bernal: Universidad Nacional de Quilmes.

Salazar Etchegaray, M. (2011). "La dimensión mediática de la estrategia de miedo y securitización en América Latina" En El Cotidiano No 107. Distrito Federal, México: Universidad Autónoma Metropolitana Unidad Azcapotzalco.

Silverstone, R. (2010). La moral de los medios de comunicación. Buenos Aires: Amorrortu Editores.

Sánchez Narvarte, E. (2015) "Procesos de privatización y concentración mediática. Una introducción al problema". Ficha de cátedra para la materia Comunicación y Medios cátedra III de la Facultad de Periodismo y Comunicación Social, Universidad Nacional de La Plata.

Tonkonoff, S. (2014). Violencia y cultura: reflexiones contemporáneas sobre Argentina. Ciudad Autónoma de Buenos Aires: CLACSO.

Villamayor, C. (2014). "Disrupción, comunicación, emancipación" En Oficios Terrestres N. 31 [en línea] Disponible en http://perio.unlp.edu.ar/ojs/index.php/oficiosterrestres/article/view/2438/2153

Williams, R. (2009). Marxismo y literatura. Buenos Aires: Las Cuarenta. 